\title{
Role of dust in the working environment in development of chronic bronchitis in British coal miners
}

\author{
J. M. ROGAN, M. D. ATTFIELD, M. JACOBSEN, S. RAE, \\ D. D. WALKER, and W. H. WALTON \\ Institute of Occupational Medicine, Edinburgh
}

Rogan, J. M., Attfield, M. D., Jacobsen, M., Rae, S., Walker, D. D., and Walton, W.H.(1973). British Journal of Industrial Medicine, 30, 217-226. Role of dust in the working environment in development of chronic bronchitis in British coal miners. In the course of a long-term prospective study of chronic respiratory disease in British coal miners the effects on pulmonary ventilatory function of exposure to airborne dust, of simple pneumoconiosis, and of chronic bronchitis have been examined in a group of 3581 coalface workers.

The men were employed in 20 collieries throughout the British coalfields. Their cumulative exposures to coal mine dust in the respirable range $(1-5 \mu \mathrm{m})$ were calculated from detailed dust sampling results at their work places during a 10-year period and from estimates of earlier exposures based on records of their industrial histories.

A progressive reduction in $\mathrm{FEV}_{\mathbf{1 . 0}}$ with increasing cumulative exposure to airborne dust has been demonstrated. This effect was evident also in a subgroup of the men studied who reported no signs of mild bronchitic symptoms (cough and phlegm for at least three months in a year).

Among men with pneumoconiosis there was no evidence of a reduction of $F V_{1.0}$ in excess of that attributable to their dust exposures, smoking habits, age, and physique.

Increasing severity of bronchitic symptoms was associated with a loss in $F_{E V} V_{1.0}$ greater than that expected from the effects of dust exposure as measured, smoking, age, and physique. Possible explanations for this phenomenon are discussed. It is suggested that the results may indicate that once early bronchitic symptoms are present the disease may progress and ventilatory capacity may deteriorate independently of factors initiating the disease process.

To what extent is occupational dust exposure responsible for respiratory disability? This question has for long been the subject of controversy and research. It was the view of the Medical Research Council (1966) that on the evidence available at the time intensity of dust exposure did not appear to be a very significant factor in determining the prevalence of bronchitis among coal miners. Several subsequent letters to the British Medical Journal challenged this conclusion, and Cochrane (1966), while accepting the Medical Research Council report as a good summary of available scientific evidence, suggested that more accurate measurements of dust dosage would be likely to yield better correlations with respiratory symptoms and ventilatory function.

Surveys in several countries have continued to show more respiratory disease among men employed in dusty as compared with non-dusty occupations (Sluis-Cremer, Walters, and Sichel, 1967; Minette, 1971; Reichel and Ulmer, 1971; Šrić and Palaić, 1971; Lloyd Davies, 1971) but results have not always been consistent (Enterline, 1967). Differences in symptom prevalence have usually been small compared with the dominant effect of smoking.

Some retrospective studies have shown an association between impaired ventilatory capacity and indices related to previous occupational dust exposures (Hyatt, Kistin, and Mahan, 1964; Lowe and 
Khosla, 1972; Becklake, Fournier-Massey, Rossiter, and McDonald, 1972) but a similar association with the prevalence of bronchitic symptoms has not always been demonstrable (Hyatt et al., 1964;McDonald, Becklake, Fournier-Massey, and Rossiter, 1972).

Gilson (1970) and Lowe and Khosla (1972) have emphasized the need for prospective studies in which respiratory symptoms are related directly to measured dust exposures. Such a study is the Pneumoconiosis Field Research of the National Coal Board. Its objective is to establish the relationship between dust and the working environment and the development of respiratory disease. After a decade of observation of face workers and environmental conditions at $\mathbf{2 0}$ collieries it was possible to establish the probability of developing pneumoconiosis in a working lifetime in varying dust concentrations (Jacobsen, Rae, Walton, and Rogan, 1970; 1971). Subsequently, among the same group of miners Rae, Walker, and Attfield (1971) showed for the first time an increase in the prevalence of bronchitis among young and middle-aged men as their cumulative dust exposures increased.

It was considered that the next step in the analysis of the data accruing from this research should be an examination of the relationship between the ventilatory capacity, as determined by the forced expired volume in one second $\left(\mathrm{FEV}_{1.0}\right)$, and the dust exposure of individuals, the radiological category of pneumoconiosis, respiratory symptoms, and other variable factors, such as smoking and physique, which would be likely to affect the FEV $_{1.0}$.

\section{Materials and methods}

Data were available from 20 collieries located in different parts of the British coalfield as described by Jacobsen et al. (1971). At each of these collieries three medical surveys had been carried out at five-year intervals and airborne dust concentrations had been measured throughout the 10-year period. The 4122 men selected for study had either been working at the coalface at the times of all three medical surveys or had worked there at the times of the first two surveys but had moved to work elsewhere underground at the time of the third survey.

The analyses in this paper are based on data obtained at the third survey. Men with progressive massive fibrosis (PMF), those under 25 years of age and those over 65 , and ex-smokers were not included. This reduced the number to 3581 .

\section{Pulmonary ventilatory function}

The Andex of pulmonary ventilatory function used was the timed forced expiratory volume $\left(\mathrm{FEV}_{1 \cdot 0}\right)$; this was measured by means of a modified Gaensler spirometer (McKerrow, McDermott, and Gilson, 1960). Four serial readings were taken: the first was discarded and a

TABLE I

Mean FEV 1.0 and Mean Height for 3581 Men $^{1}$ by Cumulative Dust Exposure, Age AND SMOKING Habits

\begin{tabular}{|c|c|c|c|c|c|c|c|c|}
\hline \multirow{3}{*}{$\begin{array}{l}\text { Estimated cumulative } \\
\text { dust exposure }\end{array}$} & & & & & & & \multicolumn{2}{|c|}{ Age } \\
\hline & \multicolumn{2}{|c|}{$25-29$} & \multicolumn{2}{|c|}{$30-34$} & \multicolumn{2}{|c|}{ 35-39 } & \multicolumn{2}{|c|}{ 40-44 } \\
\hline & $S$ & $N S$ & $S$ & $N S$ & $S$ & $N S$ & $S$ & $N S$ \\
\hline $\begin{array}{l}\text { Low } \\
\left(0-99 \mathrm{gh} / \mathrm{m}^{3}\right)\end{array}$ & $\begin{array}{c}4 \cdot 12^{2} \\
170 \cdot 7 \\
(35)\end{array}$ & $\begin{array}{l}4 \cdot 00 \\
173 \cdot 3 \\
(15)\end{array}$ & $\begin{array}{l}3 \cdot 89 \\
171 \cdot 6 \\
(99)\end{array}$ & $\begin{array}{l}3.92 \\
172 \cdot 2 \\
(25)\end{array}$ & $\begin{array}{l}3 \cdot 58 \\
171 \cdot 6 \\
(219)\end{array}$ & $\begin{array}{c}3 \cdot 63 \\
170 \cdot 7 \\
(36)\end{array}$ & $\begin{array}{l}3.34 \\
170 \cdot 5 \\
(267)\end{array}$ & $\begin{array}{c}3 \cdot 53 \\
168 \cdot 6 \\
(31)\end{array}$ \\
\hline $\begin{array}{l}\text { Medium } \\
\left(100-199 \mathrm{gh} / \mathrm{m}^{3}\right)\end{array}$ & $\begin{array}{l}4.04 \\
171.9 \\
(16)\end{array}$ & $\begin{array}{c}3 \cdot 82 \\
167 \cdot 0 \\
(9)\end{array}$ & $\begin{array}{l}3 \cdot 79 \\
173 \cdot 1 \\
(61)\end{array}$ & $\begin{array}{l}3 \cdot 54 \\
172 \cdot 9 \\
(16)\end{array}$ & $\begin{array}{l}3 \cdot 50 \\
172 \cdot 3 \\
(142)\end{array}$ & $\begin{array}{c}3 \cdot 60 \\
171 \cdot 1 \\
(21)\end{array}$ & $\begin{array}{l}3 \cdot 27 \\
171 \cdot 3 \\
(201)\end{array}$ & $\begin{array}{c}3 \cdot 26 \\
169 \cdot 0 \\
(45)\end{array}$ \\
\hline $\begin{array}{l}\text { High } \\
\left(>200 \mathrm{gh} / \mathrm{m}^{3}\right)\end{array}$ & $\begin{array}{c}3 \cdot 60 \\
172 \cdot 7 \\
(3)\end{array}$ & $\begin{array}{l}3 \cdot 88 \\
174 \cdot 0 \\
(2)\end{array}$ & $\begin{array}{l}3 \cdot 53 \\
169 \cdot 4 \\
(22)\end{array}$ & $\begin{array}{l}3 \cdot 72 \\
171 \cdot 4 \\
(14)\end{array}$ & $\begin{array}{l}3.48 \\
171 \cdot 9 \\
(60)\end{array}$ & $\begin{array}{c}3 \cdot 40 \\
172 \cdot 7 \\
(9)\end{array}$ & $\begin{array}{l}3 \cdot 11 \\
170 \cdot 1 \\
(156)\end{array}$ & $\begin{array}{c}3 \cdot 19 \\
169 \cdot 6 \\
(24)\end{array}$ \\
\hline $\begin{array}{l}\text { All dust } \\
\text { exposure groups }\end{array}$ & $\begin{array}{l}4 \cdot 07 \\
171 \cdot 2 \\
(54)\end{array}$ & $\begin{array}{l}3.93 \\
171 \cdot 2 \\
(26)\end{array}$ & $\begin{array}{l}3 \cdot 81 \\
171 \cdot 8 \\
(182)\end{array}$ & $\begin{array}{l}3 \cdot 76 \\
172 \cdot 2 \\
(55)\end{array}$ & $\begin{array}{l}3.54 \\
171.9 \\
(421)\end{array}$ & $\begin{array}{l}3 \cdot 59 \\
171 \cdot 1 \\
(66)\end{array}$ & $\begin{array}{c}3 \cdot 26 \\
170 \cdot 7 \\
(624)\end{array}$ & $\begin{array}{c}3.33 \\
169 \cdot 0 \\
(100)\end{array}$ \\
\hline \multicolumn{9}{|c|}{$\begin{array}{l}1 \text { Excluding men with PMF, those under } 25 \text {, two men over } 65 \text {, and ex-smokers } \\
{ }^{2} \text { Figures in each cell thus: }\end{array}$} \\
\hline $\begin{array}{l}\text { FEV }_{1 \cdot 0} \text { (litres) } \\
\text { Mean height (cm) } \\
\text { (Number of men) }\end{array}$ & & & & & & & & \\
\hline \multicolumn{9}{|c|}{$\mathbf{S}=$ smokers; NS $=$ non-smokers; gh $/ \mathrm{m}^{3}=$ gram hours per cubic metre } \\
\hline
\end{tabular}


mean result was based on the second, third, and fourth expirations.

\section{Respiratory symptoms questionnaire}

A respiratory symptoms questionnaire, based on that recommended by the Medical Research Council (1961), was completed. Details of its validity and reproducibility have been documented by Rae et al. (1971). The number of cigarettes and the amount of pipe tobacco smoked per day was recorded. One ounce of tobacco was considered equivalent to 30 cigarettes. 'Non-smokers' were defined as those who have never smoked as much as one cigarette a day for one year. Replies to the questionnaire were classified into four groups, corresponding to increasing severity of respiratory symptoms. These groups, which may be regarded as different 'grades' of chronic bronchitis, were defined as follows:

Grade 0 no symptoms-or symptoms not amounting to those of bronchitis grade 1 ;

Grade 1 cough and phlegm on most days for at least three months for at least one year (men with grades 2 and 3 are not included in this group);

Grade 2 cough and phlegm on most days for at least three months for at least one year, together with a history of chest illness keeping the subject off work for more than one week in the last three years (men with grade 3 are not included in this group);

Grade 3 cough and phlegm on most days for at least three months for at least one year, a history of chest illness, and symptoms of breathlessness on moderate exertion (walking on level ground).

\section{Radiology}

Full size chest radiographs were taken of all subjects at each survey and were categorized for pneumoconiosis by eight film readers in the manner described by Jacobsen et al. (1971). For the present analysis, films classified according to the 12-point scale described by Liddell and Lindars (1969) were allocated to one of the four categories of simple pneumoconiosis on the ILO (1959) scale. Complicated pneumoconiosis (PMF) was accepted as being present when it was diagnosed by two or more of the eight readers.

\section{Dust exposures}

During the 10 years interval between the first and third surveys airborne dust concentrations had been measured in considerable detail at each colliery (Jacobsen et al., 1970). From records of the time each subject had spent in various defined occupational groups and a knowledge of the concentration of dust to which these groups had been exposed an exposure index (concentration $\times$ time) was calculated for every man in the sample. For the period prior to the first survey and starting at the time the individual joined the industry there were no detailed records of the dust concentrations to which he had been exposed, but an industrial history had been taken for each man. This recorded the jobs undertaken, the time spent at them, and the collieries and the coal seams in

\begin{tabular}{|c|c|c|c|c|c|c|c|c|c|}
\hline \multicolumn{2}{|c|}{$45-49$} & \multicolumn{2}{|c|}{$50-54$} & \multicolumn{2}{|c|}{$55-59$} & \multicolumn{2}{|c|}{$60-64$} & \multicolumn{2}{|c|}{$\begin{array}{l}\text { All age } \\
\text { groups }\end{array}$} \\
\hline $\begin{array}{r}3.01 \\
-\quad 168.9 \\
(184)\end{array}$ & $\begin{array}{c}3 \cdot 25 \\
170 \cdot 9 \\
(26)\end{array}$ & $\begin{array}{c}2 \cdot 90 \\
168 \cdot 3 \\
(127)\end{array}$ & $\begin{array}{c}3.01 \\
165 \cdot 3 \\
(23)\end{array}$ & $\begin{array}{c}2 \cdot 52 \\
168 \cdot 1 \\
(80)\end{array}$ & $\begin{array}{c}2 \cdot 83 \\
170 \cdot 2 \\
(10)\end{array}$ & $\begin{array}{l}2 \cdot 20 \\
166 \cdot 5 \\
(50)\end{array}$ & $\begin{array}{c}3.08 \\
164 \cdot 3 \\
(4)\end{array}$ & $\begin{array}{r}3 \cdot 24 \\
169 \cdot 9 \\
(1061)\end{array}$ & $\begin{array}{r}3.49 \\
169.9 \\
(170)\end{array}$ \\
\hline $\begin{array}{r}2.82 \\
\quad 169.6 \\
-\quad(158)\end{array}$ & $\begin{array}{c}3.02 \\
168 \cdot 9 \\
(30)\end{array}$ & $\begin{array}{c}2 \cdot 49 \\
168 \cdot 4 \\
(216)\end{array}$ & $\begin{array}{l}2 \cdot 73 \\
167 \cdot 8 \\
(34)\end{array}$ & $\begin{array}{c}2 \cdot 21 \\
167 \cdot 3 \\
(167)\end{array}$ & $\begin{array}{c}2 \cdot 52 \\
167 \cdot 0 \\
(35)\end{array}$ & $\begin{array}{c}2 \cdot 13 \\
166 \cdot 7 \\
(111)\end{array}$ & $\begin{array}{c}2 \cdot 29 \\
165 \cdot 5 \\
(20)\end{array}$ & $\begin{array}{c}2 \cdot 66 \\
168 \cdot 8 \\
(893)\end{array}$ & $\begin{array}{l}2 \cdot 88 \\
168 \cdot 4 \\
(168)\end{array}$ \\
\hline
\end{tabular}


which he had worked and gave details of any substantial period of absence from the industry. From these records information was extracted on the time which had been spent in the most dusty jobs, i.e., work at the coal face or on development in coal and stone. To estimate the exposure for this period this time was multiplied by the mean annual concentration to which the individual had been exposed during the five years between the first and second surveys. The total exposure of each individual was then compiled by the addition of his exposure for the period prior to the first survey to that measured for the period between the first and second, and second and third surveys. These measurements were expressed as gram hours per cubic metre $\left(\mathrm{gh} / \mathrm{m}^{3}\right)$ of sampled air. The units refer to the time weighted cumulative mass concentration of dust particles in the respirable size range. These particles were mostly less than $5 \mu \mathrm{m}$ nominal diameter according to the MRC/Johannesburg criterion (Hamilton and Walton, 1961). Further details of the composition and characteristics of the sampled dust have been reported by Dodgson, Hadden, Jones, and Walton (1971).

\section{Results}

Table 1 shows the mean $\mathrm{FEV}_{1.0}$ results in relation to three arbitrarily defined ranges of dust exposures (low, medium, and high), age groups, and smoking habits.

A decrease in $\mathrm{FEV}_{\mathbf{1 . 0}}$ with increasing dust exposure is apparent immediately in nearly all the age/ smoking-habit subgroups. The loss of ventilatory capacity with increasing age is evident also and the reduced $\mathrm{FEV}_{1.0}$ for smokers, as compared with non-

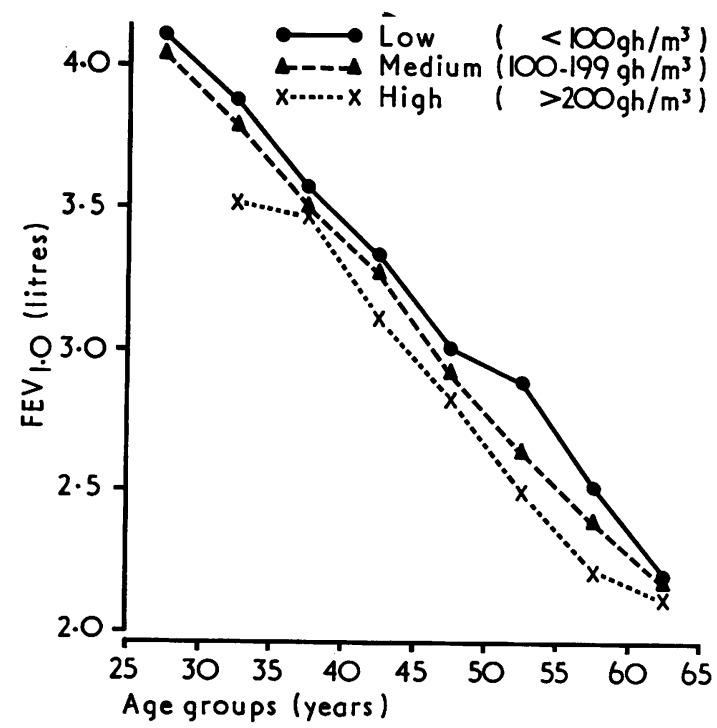

FIG. 1. Relationship between mean $\mathrm{FEV}_{1 \cdot 0}$ and age among smokers, grouped according to cumulative dust exposures (age-groups with less than five men not included). smokers, is demonstrated in all three dust exposure groups. Figures 1 and 2 illustrate the results for smokers and non-smokers. The relatively small number of non-smokers among the men studied (approximately one-seventh of the total) is reflected in the greater variability of mean results evident in Figure 2.

Analyses were made in order to quantify the effect apparently associated with dust exposure, to verify its statistical significance, and to assess its importance in relation to other variables affecting FEV $_{1.0}$. Tables 2, 3, 4 and 5 show the results which are discussed below. Multiple regression methods were used. With this approach several factors acting simultaneously on one variable, such as FEV $_{1.0}$, may be studied. Possible interactions between the factors can be considered. Details of the statistical analyses are described in an Appendix. The main findings were as follows.

The association between the reduction in $\mathrm{FEV}_{1.0}$ and increasing dust exposure is statistically highly significant $(P<0.001)$. A cumulative dust exposure at the level of the mean exposure of the group studied is associated with a loss of 0.10 litre. This is slightly more than the loss associated with two years increase in age or with smoking 20 cigarettes per day.

Men with no radiological signs of pneumoconiosis had higher mean FEV ${ }_{1.0}$ levels than those with pneumoconiosis. The difference is attributable mainly to the fact that men with pneumoconiosis were

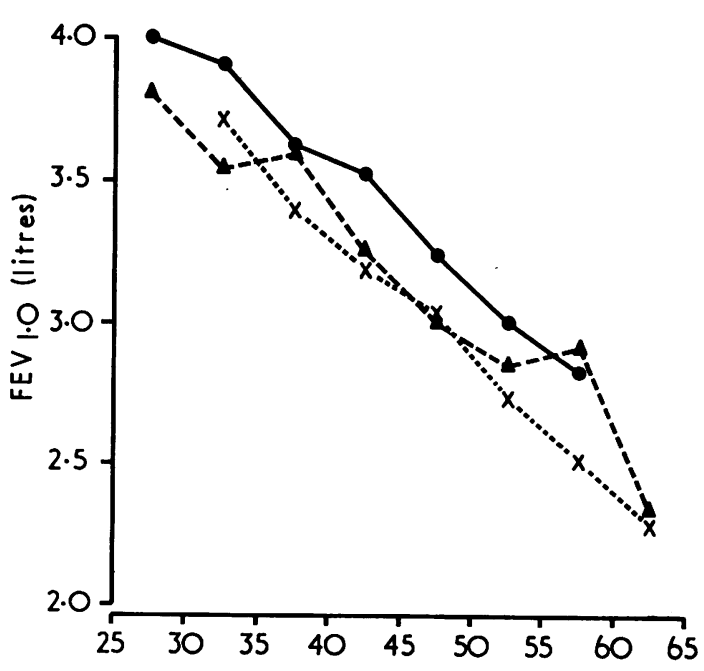

FIG. 2. Relationship between mean $\mathrm{FEV}_{1 \cdot 0}$ and age among non-smokers, grouped according to cumulative dust exposures (age-groups with less than five men not included). 
TABLE 2

Multiple Regression ANalysis of FEV 1.0 Results from 3581 Men Aged between 25 and 64

\begin{tabular}{l|c|c|c|c|c}
\hline \multicolumn{1}{c|}{ Variable } & Units & Mean & $\begin{array}{c}\text { Regression } \\
\text { co-efficient }\end{array}$ & $\begin{array}{c}\text { Standard } \\
\text { error }\end{array}$ & $\begin{array}{c}\text { Significance } \\
\text { P< }\end{array}$ \\
\hline Dust exposure & gh/m & 174.8 & -0.0006 & 0.0001 & 0.001 \\
Smoking & cigs/day & 13.1 & -0.0046 & 0.0011 & 0.001 \\
Age & years & 47.0 & -0.0471 & 0.0012 & 0.001 \\
Height & cm & 169.6 & 0.0306 & 0.0025 & 0.001 \\
Sitting height & cm & $90 \cdot 1$ & 0.0086 & 0.0048 & 0.1 \\
Weight & kg & 72.2 & 0.0034 & 0.0010 & 0.001 \\
\hline
\end{tabular}

Constant $=-0.84$ litre

Residual standard deviation $=\mathbf{0 . 3 2}$ litre

Degrees of freedom $=3574$

TABLE 3

Mean Results by Category of Simple Pneumoconiosis

\begin{tabular}{|c|c|c|c|c|}
\hline & \multicolumn{4}{|c|}{ Pneumoconiosis category } \\
\hline & 0 & 1 & 2 & 3 \\
\hline $\begin{array}{l}\text { No. of men } \\
\text { Observed FEV } 1.0 \\
\text { (litres) }\end{array}$ & $\begin{array}{r}3005 \\
3.04\end{array}$ & $\begin{array}{c}415 \\
2 \cdot 73\end{array}$ & $\begin{array}{l}145 \\
2 \cdot 77\end{array}$ & $\begin{array}{l}16 \\
2 \cdot 76\end{array}$ \\
\hline $\begin{array}{l}\text { Expected FEV } 1.0^{1} \\
\text { (litres) }\end{array}$ & 3.05 & $2 \cdot 73$ & $2 \cdot 66$ & $2 \cdot 74$ \\
\hline $\begin{array}{l}\text { Dust exposure } \\
\left(\mathrm{gh} / \mathrm{m}^{3}\right)\end{array}$ & $154 \cdot 46$ & $270 \cdot 25$ & $309 \cdot 27$ & $304 \cdot 66$ \\
\hline $\begin{array}{l}\text { Smoking } \\
\text { (cigs/day) }\end{array}$ & $13 \cdot 42$ & $12 \cdot 10$ & $10 \cdot 57$ & $11 \cdot 69$ \\
\hline $\begin{array}{l}\text { Age (years) } \\
\text { Height (cm) } \\
\text { Sitting height (cm) } \\
\text { Weight (kg) }\end{array}$ & $\begin{array}{r}46 \cdot 22 \\
169 \cdot 68 \\
90 \cdot 19 \\
72 \cdot 56\end{array}$ & $\begin{array}{r}51 \cdot 24 \\
169 \cdot 11 \\
89 \cdot 78 \\
70 \cdot 54\end{array}$ & $\begin{array}{r}51 \cdot 52 \\
168 \cdot 21 \\
89 \cdot 37 \\
69 \cdot 77\end{array}$ & $\begin{array}{r}52 \cdot 38 \\
171 \cdot 56 \\
90 \cdot 13 \\
72 \cdot 38\end{array}$ \\
\hline
\end{tabular}

${ }^{1}$ Expected FEV $_{1.0}$ for each man calculated from fitted regression equation; see Table 2

TABLE 4

Mean Results by Grade of Bronchitis

\begin{tabular}{|c|c|c|c|c|}
\hline & \multicolumn{4}{|c|}{ Bronchitis grade } \\
\hline & 0 & 1 & 2 & 3 \\
\hline $\begin{array}{l}\text { No. of men } \\
\text { Observed FEV } \\
\text { Expected FEV }_{1.0} \text { (litres) } \\
\left.\text { Dust exposure (gh/m } \text { (litr) }^{3}\right) \\
\text { Smoking (cigs/day) } \\
\text { Age (years) } \\
\text { Height (cm) } \\
\text { Sitting height (cm) } \\
\text { Weight (kg) }\end{array}$ & $\begin{array}{r}2272 \\
3 \cdot 17 \\
3 \cdot 07 \\
162 \cdot 58 \\
12 \cdot 10 \\
45 \cdot 83 \\
169 \cdot 73 \\
90 \cdot 26 \\
72 \cdot 81\end{array}$ & $\begin{array}{r}879 \\
2 \cdot 82 \\
2 \cdot 90 \\
187 \cdot 60 \\
15 \cdot 39 \\
48 \cdot 48 \\
169 \cdot 40 \\
89 \cdot 99 \\
71 \cdot 90\end{array}$ & $\begin{array}{r}183 \\
2 \cdot 69 \\
2 \cdot 93 \\
175 \cdot 36 \\
15 \cdot 12 \\
47 \cdot 55 \\
168 \cdot 93 \\
89 \cdot 73 \\
69 \cdot 97\end{array}$ & $\begin{array}{r}247 \\
2 \cdot 22 \\
2 \cdot 64 \\
241 \cdot 51 \\
13 \cdot 29 \\
52 \cdot 82 \\
169 \cdot 00 \\
89 \cdot 44 \\
69 \cdot 53\end{array}$ \\
\hline
\end{tabular}

${ }^{1}$ Expected $\mathrm{FEV}_{1 \cdot 0}$ for each man calculated from fitted regression equation; see Table 2 
TABLE 5

Mean Differences: $\left(\right.$ FEV $_{1 \cdot 0}$ ObServed-FEV $_{1 \cdot 0}$ Expected), in Litres, by Category of Pneumoconiosis AND GRADE OF BRONCHITIS

\begin{tabular}{|c|c|c|c|c|c|}
\hline \multirow{2}{*}{$\begin{array}{c}\text { Category of } \\
\text { pneumoconiosis }\end{array}$} & \multicolumn{4}{|c|}{ Grade of bronchitis } & \multirow{2}{*}{ All grades } \\
\hline & 0 & 1 & 2 & 3 & \\
\hline 0 & $\begin{array}{c}0 \cdot 10 \\
(1960)^{1}\end{array}$ & -0.10 & -0.27 & -0.57 & $\begin{array}{l}-0.01 \\
(3005)\end{array}$ \\
\hline 1 & $0 \cdot 10$ & -0.05 & $-0 \cdot 16$ & -0.20 & 0.00 \\
\hline & (230) & (107) & (23) & (55) & (415) \\
\hline 2 & $\begin{array}{r}0 \cdot 16 \\
(77)\end{array}$ & -0.00 & $0 \cdot 10$ & $\begin{array}{l}0.11 \\
(18)\end{array}$ & $\begin{array}{c}0.11 \\
0145)\end{array}$ \\
\hline 3 & 0.04 & 0.05 & $\begin{array}{c}(7) \\
-0 \cdot 15\end{array}$ & -0.08 & 0.02 \\
\hline & (5) & (6) & (2) & (3) & (16) \\
\hline $\begin{array}{c}\text { All } \\
\text { categories }\end{array}$ & $\begin{array}{c}0 \cdot 10 \\
(2272)\end{array}$ & $\begin{array}{l}-0.08 \\
(879)\end{array}$ & $\begin{array}{l}-0.24 \\
(183)\end{array}$ & $\begin{array}{l}-0.43 \\
(247)\end{array}$ & \\
\hline
\end{tabular}

${ }^{1}$ (Number of men in each subgroup in parentheses)

Expected $\mathrm{FEV}_{1.0}$ for each man calculated from fitted regression equation; see Table 2

older and had higher dust exposures on average (Table 3). There was no evidence that men with different categories of pneumoconiosis suffered a loss in lung function in excess of that attributable to their dust exposures, smoking habits or other variables considered.

Increasing severity of bronchitic symptoms was associated with a loss in FEV $_{1.0}$ greater than that expected from the effects of dust exposure, smoking, age, height, and weight. The effect is substantial and very unlikely to be due to chance. The mean FEV $_{1.0}$ for the 247 men with grade 3 bronchitis in this study was 2.22 litres; yet their ages, smoking habits, dust exposures, and anthropometric measurements suggest that it should have been 2.65 litres. The difference, 0.43 litre, is equivalent approximately to the effect of 10 years increase in age.

The study confirms that cigarette smoking is associated with a statistically significant loss of FEV $_{1.0}$. The effect appears to be additional to those associated with dust exposure, age, and physique; there was no evidence of an interaction between cigarette smoking and dust exposure.

\section{Discussion}

This report is one of a series dealing with the analysis of data concerning a group of face workers employed at 20 different collieries representative of the various environmental conditions in the coalfields of the United Kingdom. Interpretation of results found in a sample of this type requires caution. The working population from which the sample was drawnexcludes all men who left the industry during the 10-year period when dust measurements were made. Some of these men may have been affected by their exposures to dust more severely than those who remained in the industry. The omission of results from such subjects may have biased the estimates of relationships found.

A further selection effect is introduced because work at the coal face is arduous and only the reasonably fit can remain there. In a study of all working miners from eight of the collieries contributing data to the present report it was shown that the $\mathrm{FEV}_{\mathbf{1 . 0}}$ tended to fall with increasing category of pneumoconiosis (Rogan et al., 1961). To some extent at least this result may now be interpreted as a reflection of what are likely to have been higher average dust exposures among men with pneumoconiosis. Nevertheless, it may be that radiological changes are associated with an additional, albeit relatively small, loss of lung function. The fact that no such effect is shown in the present analysis (Tables 3 and 5) may be due in part to the selected nature of the sample. Men with pneumoconiosis and more severe respiratory disability may have transferred from underground work to work on the surface. Such men will not have been included in this study and the results may be biased to that extent.

Men aged less than 25 were excluded from the analysis because ventilatory capacity normally increases with age until a peak is reached between the ages of 21 and 25 . Two men over 65 were also excluded. Ex-smokers were omitted because it was considered that their inclusion might obscure any effect attributable to tobacco. Ventilatory capacity is usually reduced in the presence of PMF (Gilson and Hugh Jones, 1955; Cotes, 1968). The pathogenesis of PMF remains obscure but there is general agreement that factors are almost certainly involved which are as yet unidentified but are in addition to dust exposure and the other variables considered 
here. For this reason results from men with PMF were not included in the analysis.

It is considered that these exclusions are justifiable because the main aim of this study was to identify and estimate a relationship between the level of $\mathrm{FEV}_{1.0}$ and dust exposure; results from the analysis might have been misleading if men had been included who suffered from impaired $\mathrm{FEV}_{\mathbf{1 . 0}}$ produced by factors independent of dust exposure and not accounted for by any of the other variables considered. If any bias has been introduced as a result of these omissions then this is likely to have resulted in some underestimation, rather than an exaggeration, of the effect of occupational exposure on respiratory function.

The exposure index used in this paper includes a component which had been calculated from an estimate of the dust concentrations the individual had worked in prior to the period when detailed measurements of the airborne dust were made. It was assumed that the mean dust concentration experienced by an individual during the first five years of the period when field measurements were made would be a sensible estimate of the mean concentration to which he had been exposed in the preceding period. Although it has been shown by Rae et al. (1971) that estimates of occupational dust exposure calculated in this way correlate closely with the prevalence of pneumoconiosis in the group of miners under study, the accuracy of the dose-response relationship found is dependent on the validity of the assumption made in calculating the 'estimated' component of the exposure index.

A further difficulty associated with the exposure index used arises from differences in the lengths of time during which the estimated cumulative exposures were incurred. For the young men it may have been over a 10-year period while for the older men it may have been over a period of 40 years. There is some evidence (Reisner, 1971) that the dose rate and the period during which the rate is highest may be significant factors in determining the biological response. An interaction between cumulative dust exposure and age found in the present study (see Appendix) may be a reflection of this phenomenon. The interaction could be interpreted as an indication that a particular exposure experienced over a relatively short period of time (among the younger men) has a more pronounced effect on the level of FEV $_{1.0}$ than the same total exposure accumulated over a longer period (among the older men). If this is so then the results from the analysis including the interaction term may provide the best guide to the likely effect on $\mathrm{FEV}_{\mathbf{1 . 0}}$ of particular mean dust concentrations experienced over a working life at the coal face. A 35-year working life at the face may be taken as equivalent to approximately 60900 working hours. A dust concentration averag- ing $4 \mathrm{mg} / \mathrm{m}^{3}$, for instance, over this period would result in a total exposure of $244 \mathrm{gh} / \mathrm{m}^{3}$. The fitted equation including the interaction term predicts that for a man aged 55 such an exposure would be expected to have reduced his FEV $_{1.0}$ by 0.12 litre. The simpler equation (Table 2) without the interaction term suggests that $244 \mathrm{gh} / \mathrm{m}^{3}$ would be associated with a loss of $0 \cdot 15$ litre. Since these predictions are similar, and since the effect of the interaction is small numerically in the region of the mean age of the group studied, the results are discussed further in terms of the estimates shown in Table 2.

During the 10-year period covered by the research dust concentrations were measured in the size range 1-5 $\mu \mathrm{m}$ (Dodgson et al., 1971). This was the range generally considered to be important in relation to pneumoconiosis but it is by no means certain that it is the appropriate one in relation to the pathogenesis of bronchitis. It is possible that the particles greater than $5 \mu \mathrm{m}$ in diameter which settle on the walls of the bronchi before they reach the alveoli play at least as important a role as the smaller ones. The estimate of the effect of dust on $\mathrm{FEV}_{\mathbf{1 . 0}}$ in the present analysis relates only to the so-called respirable fraction of airborne dust in the mine atmosphere to which men were exposed.

When reporting surveys of symptom prevalence authors have defined chronic bronchitis in various ways. Some have considered only cough and sputum, others have included a history of chest illness while others again have made the presence of breathlessness an essential criterion. The results from the present study demonstrate that a respiratory symptoms questionnaire may be used to define grades of bronchitis which are associated with different levels of $\mathrm{FEV}_{1.0}$ (Tables 4 and 5). Grade 0 was defined as 'no symptoms amounting to grade 1'. A separate analysis (described in the Appendix) of results from men classified in grade 0 shows that within this subgroup the effect of dust exposure on $F_{E V_{1.0}}$ was very similar to that estimated for all subjects. Thus it appears that chronic nonspecific obstructive airways disease may occur among men apparently without 'chronic bronchitis' when that condition is defined solely in terms of replies to a questionnaire. This emphasizes the importance of precise definition of bronchitis in epidemiological studies of ventilatory impairment.

There was close agreement between the mean FEV $_{1.0}$ observed among men with category 0 simple pneumoconiosis and the mean level expected when due allowance is made for variations in dust exposures and other factors listed in Table 3. The relationship between dust exposure and $\mathrm{FEV}_{\mathbf{1 . 0}}$ described in this paper is thus shown to be valid for men whose radiographs are classified as category 0 . The result is consistent with the report from Hyatt et al. (1964) who showed that maximal mid- 
expiratory flow among West Virginian coal miners with category 0 pneumoconiosis was related to the number of years worked underground.

This study has shown a relationship between loss of ventilatory capacity of individual men and their cumulative exposures to respirable coal dust as estimated from environmental measurements made close to the men over a 10-year period. Becklake et al. (1972) have found a similar effect among chrysotile asbestos workers. These authors considered a large number of lung function tests. The FEV $_{1.0}$ was among those which showed clearly that lung function was depressed increasingly with increasing dust exposure in both smokers and nonsmokers.

Becklake et al. (1972) discuss the suitability of lung function tests for surveillance of men exposed to occupational dust hazards. These authors note that the early effects of dust exposure were detected more easily among non-smokers than among smokers. They suggest that the effects of dust exposure and cigarette smoke may not be additive. Sluis-Cremer et al. (1967) have reported a potentiating effect between dust exposure and cigarette smoking on symptomatology among South African mineworkers. No such interaction is evident in the study of coal miners reported now, and nothing in the results could be interpreted as supporting the speculation by Becklake et al. (1972) that smoking may have a protective effect against dust exposure.

However, the results in Tables 4 and 5 show that increasing severity of bronchitic symptoms is associated with a reduction in $\mathrm{FEV}_{1.0}$ over and above that to be expected from the effects of smoking and dust exposure as estimated in the analysis.One possible explanation for this result is that these exposures refer only to dust particles in the respirable range as defined above: it may be that more severe bronchitis, and corresponding further loss of lung function, occurred among men who had been exposed to higher concentrations of bigger dust particles, which were not measured. The possibility has also been considered that the excess respiratory disability was occasioned by general environmental pollution. However, an examination of published data on pollution in the proximity of 17 of the 20 collieries involved does not support this suggestion. An alternative explanation for the results shown in Tables 4 and 5 would be to suppose that when certain pathological changes associated with respiratory symptoms have occurred, bronchitis may become progressive independently of factors initiating the disease process. Respiratory symptoms would then become more severe and ventilatory capacity would be further impaired. An effect of this kind would be expected to obscure the relationship between exposure to dust and loss of lung function in certain circumstances, and may contribute to the apparent interactions between dust exposure and smoking noted in some surveys, since smoking itself is undoubtedly an important factor initiating bronchitic symptoms.

This suggestion is consistent with the comment by Hyatt $e t$ al. (1964) that if miners develop respiratory symptoms during the first year of underground work then these symptoms persist. The theory helps also to explain why Rae et al. (1971) were able to relate prevalence of bronchitic symptoms to dust exposure only among the younger coal miners they studied, and why McDonald et al. (1972) found a similar relationship only among the nonsmoking and light smoking asbestos workers in their survey. Older men, particularly those who smoke, are more likely to have bronchitic symptoms than younger men. If further deterioration were to occur, unrelated to subsequent dust exposure or other variables known to affect the development of bronchitis, then this may be expected to distort the overall relationship with dust.

Another result reported by Rae et al. (1971) was that coal miners with $x$-ray changes indicative of pneumoconiosis reported bronchitic symptoms more frequently than other miners, irrespective of age or smoking habits. At least some of this difference can be attributed to the higher dust exposures experienced, on average, by men with pneumoconiosis. If, as suggested above, bronchitis can progress independently when a certain stage has been reached then this may have inflated the excess symptom prevalence among men with radiological changes. However, the data presented by Rae et al. (1971) do not support the concept of a potentiation between airborne dust and tobacco smoke. Such a phenomenon would result in a more pronounced effect of dust exposure among smokers as compared with non-smokers. In fact the difference in symptom prevalence between men with and without radiological changes was consistently bigger among non-smokers than smokers. Similarly, Lowe and Khosla (1972) found that the difference in lung function between ex-miners and non-miners working in the steel industry was greater among non-smokers than smokers.

The current standards for airborne dust in British coal mines were introduced in 1970 and were designed to ensure that long-term average dust concentrations at coal faces would not exceed about $4 \mathrm{mg} / \mathrm{m}^{3}$ (Jacobsen et al., 1970). Over a 35-year working life at the coalface such a mean concentration would result in a cumulative dust exposure of $240 \mathrm{gh} / \mathrm{m}^{3}$, and the results reported now suggest that this would be associated with a reduction in $\mathrm{FEV}_{\mathbf{1 . 0}}$ of about $150 \mathrm{ml}$. This estimate must be regarded as approximate only since the cumulative dust exposures used in the analysis are themselves approximations and the relationships are subject to possible 
biases as discussed above. However, the ventilatory impairment as estimated is unlikely to be of clinical importance, and although the estimate represents an average expected loss in $\mathrm{FEV}_{1.0}$ the statistical analysis suggests that even the most severely disabled $1 \%$ of men exposed to $4 \mathrm{mg} / \mathrm{m}^{3}$ over 35 years are unlikely to suffer a loss in $\mathrm{FEV}_{1.0}$ greater than about $200 \mathrm{ml}$ as a result of their dust exposures. It follows that the dust standards now in force in British coal mines, which were established in order to reduce the incidence of pneumoconiosis, are likely also to contain the risk of men developing clinically significant obstructive airways disease as a result of dust exposure in coal mines.

Equally it must be accepted that higher levels of dust exposure resulting from failure to implement the current standard are associated with clinically important disability. This is seen clearly in the results reported now, since some $10 \%$ of the coalface workers considered had exposures in excess of $440 \mathrm{gh} / \mathrm{m}^{3}$ while still working underground, and such exposures are associated with reductions in $\mathrm{FEV}_{1.0}$ of $250 \mathrm{ml}$ or higher.

These considerations, and the results from the other studies referred to above, underline the importance of reducing dust concentrations in all work places where there may be a hazard. Such measures would be expected not only to reduce the incidence of pneumoconiosis but would also avoid unnecessary loss of lung function among exposed men.

\section{References}

Becklake, M. R., Fournier-Massey, G., Rossiter, C. E., and McDonald, J. C. (1972). Lung function in chrysotile asbestos mine and mill workers of Quebec. Archives of Environmental Health, 24, 401-409.

Cochrane, A. L. (1966). Chronic bronchitis and occupation. British Medical Journal, 1, 858-859.

Cotes, J. E. (1968). Lung Function, 2nd ed., p. 448. Blackwell Scientific Publications, Oxford.

Davies, T. A. Lloyd (1971). Respiratory Disease in Foundrymen. Report of a Survey. Department of Employment, H.M.S.O., London.

Dodgson, J., Hadden, G. G., Jones, C. O., and Walton, W. H. (1971). Characteristics of the airborne dust in British coal mines. In Inhaled Particles III, edited by W. H. Walton, Vol II, pp. 757-781. Unwin, Old Woking, Surrey.

Enterline, P. E. (1967). The effects of occupation on chronic respiratory disease. Archives of Environmental Health, 14, 189-200.

Gilson, J. C. (1970). Occupational bronchitis? Proceedings of the Royal Society of Medicine, 63, 857-864.

Pneumoconiosis. Special Report Series Medical Research Council, London, no. 290.

Hamilton, R. J., and Walton, W. H. (1961). The selective sampling of respirable dust. In Inhaled Particles and Vapours, edited by C. N. Davies, pp. 465-475. Pergamon, Oxford.

Hyatt, R. E., Kistin, A. D., and Mahan, T. K. (1964). Respiratory disease in Southern West Virginia coal miners. American Review of Respiratory Disease, 89, 387-401.

International Labour Office (1959). Meeting of experts on the international classification of radiograpns of the pneumoconioses. Occupational Safety and Health, 9, 63-69.

Jacobsen, M., Rae, S., Walton, W. H., and Rogan, J. M. (1970). New dust standards for British coal mines. Nature, 227, 445-447.

$-\longrightarrow,-$, and $-(1971)$. The relation between pneumoconiosis and dust-exposure in British coal mines. In Inhaled Particles III, edited by W. H. Walton, pp. 903-917. Unwin, Old Woking, Surrey.

Liddell, F. D. K., and Lindars, D. C. (1969). An elaboration of the I.L.O. classification of simple pneumoconiosis. British Journal of Industrial Medicine, 26, 89-100.

Lowe, C. R., and Khosla, T. (1972). Chronic bronchitis in ex-coal miners working in the steel industry. British Journal of Industrial Medicine, 29, 45-49.

McDonald, J. C., Becklake, M. R., Fournier-Massey, G., and Rossiter, C. E. (1972). Respiratory symptoms in chrysotile asbestos mine and mill workers of Quebec. Archives of Environmental Health, 24, 358-363.

McKerrow, C. B., McDermott, M., and Gilson, J. C. (1960). A spirometer for measuring the forced expiratory volume with a simple calibrating device. Lancet, 1, 149-151.

Medical Research Council (1961). Instructions for the use of the Short Questionnaire on Respiratory Symptoms, 1960.

(1966) Chronic bronchitis and occupation. British Medical Journal, 1, 101-102.

Minette, A. (1971). Role de l'empoussiérage professionnel dans la production des bronchites chroniques des mineurs de charbon. In Inhaled Particles III, edited by W. H. Walton, pp. 873-881. Unwin, Old Woking, Surrey.

Rae, S., Walker, D. D., and Attfield, M. D. (1971). Chronic bronchitis and dust exposure in British coalminers. In Inhaled Particles III, edited by W. H. Walton, pp. 883-894. Unwin, Old Woking, Surrey.

Reichel, G., and Ulmer, W. T. (1971). The inter-relationship of coalminers' pneumoconiosis and bronchitis (an epidemiological study on 946 steel workers and 1319 coalminers). In Inhaled Particles III, edited by W. H. Walton, pp. 897-900. Unwin, Old Woking, Surrey.

Reisner, M. T. R. (1971). Results of epidemiological studies of pneumoconiosis in West German coal mines. In Inhaled Particles III, edited by W. H. Walton, pp. 921-931. Unwin, Old Woking, Surrey.

Rogan, J. M., Ashford, J. R., Chapman, P. J., Duffield, D. P., Fay, J. W. J., and Rae, S. (1961). Pneumoconiosis and respiratory symptoms in miners at 8 collieries. British Medical Journal, 1, 1337-1342.

Sarić, M., and Palaić, S. (1971). The prevalence of respiratory symptoms in a group of miners and the relationship between the symptoms and some functional parameters. In Inhaled Particles III, edited by W. H. Walton, pp. 863-870. Unwin, Old Woking, Surrey.

Sluis-Cremer, G. K., Walters, L. G., and Sichel, H. S. (1967). Chronic bronchitis in miners and non-miners: An epidemiological survey of a community in the goldmining area in the Transvaal. British Journal of Industrial Medicine, 24, 1-12.

\section{Appendix}

This Appendix describes how the results were interpreted. The method of multiple regression was used and the following variables were considered: age, height, sitting height, weight, the number of cigarettes smoked per day, and cumulative dust exposure. In the first instance it was assumed that the combined effects of these different variables on any one man 
could be represented by the sum of independent effects associated with each variable. The regression coefficients in Table 2 are the estimates of these effects from the data; they indicate the expected change in $\mathrm{FEV}_{\mathbf{1 . 0}}$ (in litres) per unit increase in the variable concerned. The probability that the effect apparently associated with sitting height is a statistical artefact is less than $10 \%$. There is no ambiguity about the statistical significance of effects associated with the other variables listed in Table $2(\mathrm{P}<0.001)$. The level of $\mathrm{FEV}_{1.0}$ expected for any particular man may be calculated from the fitted regression equation. For instance, the expected $\mathrm{FEV}_{1.0}$ for a man for whom all the variables are precisely the mean values found in the whole group would be $[(47.0 \times(-0.0471)]+[(169.6) \times(0.0306)]+$ $[(90.1) \times(0.0086)]+[(72.2) \times(0.0034)]+$ $[(13.1) \times(-0.0046)]+[(174.8) \times(-0.0006)]-$ $0.84=2.99$ litres.

It will be seen that in the age range considered ( 25 to 64 years) the $\mathrm{FEV}_{1.0}$ is reduced by 0.0471 litre for each additional year of age. Thus, other things being equal, a man aged 47 may be expected to have an $\mathrm{FEV}_{1.0}$ about half a litre lower than a man aged 37 . The loss associated with dust exposure is $0.0006 \mathrm{litre} / \mathrm{gh}$ per $\mathrm{m}^{3}$. If the hypothetical man whose expected $\mathrm{FEV}_{\mathbf{1 . 0}}$ was calculated above had not been exposed to any respirable dust then it is expected that this $\mathrm{FEV}_{\mathbf{1 . 0}}$ would have been increased by $174.8 \times 0.0006=0.10$ litre, that is, to 3.09 litres. If, in addition, he had not smoked, then his expected $\mathrm{FEV}_{1.0}$ would be increased by $13.1 \times$ $0.0046=0.06$ litre, that is, to 3.15 litres.

The validity of the above model, in which all the effects are assumed to be simply additive, was examined by considering the possibility that the effect of one variable might be modified depending on the level of another. Appropriate interaction terms were inserted into the regression equation and tested for statistical significance. An apparent reduction in the effect of dust exposure with increasing age was statistically highly significant $(P<0.001)$. Dust exposure was estimated as reducing $\mathrm{FEV}_{1.0}$ by 0.0011 litre/gh per $\mathrm{m}^{3}$ at age 25 and by 0.0003 litre/gh per $\mathrm{m}^{3}$ at age 64 . For men aged 47 the estimated dust effect was the same as that shown in Table 2. There appeared to be also an even smaller (but statistically significant) interaction between height and age. This aspect of the results is being studied further. However, there was no evidence of an interaction between dust exposure and the number of cigarettes smoked per day.

Analyses were made of the differences between the values of $\mathrm{FEV}_{1.0}$ observed for each man and those calculated from the fitted equation. The magnitude of these differences (observed-expected) indicate the extent to which the observed results are explicable in terms of the estimated effects listed in Table 2.
Of particular interest is the question whether the presence of radiological signs of pneumoconiosis might have an independent effect on $\mathrm{FEV}_{1.0}$, over and above that expected from the variables included in the equation. Results from men grouped according to category of pneumoconiosis are given in Table 3, and this shows that there is no evidence for such an additional effect. The differences between the mean observed $\mathrm{FEV}_{1.0}$ results and the mean of those expected (given the differences in dust exposures, ages, smoking habits, and anthropometric measurements between groups) are small and show no pattern that can be related to severity of pneumoconiosis. It is clear that the higher mean expected (and observed) $\mathrm{FEV}_{1.0}$ results for men without pneumoconiosis is due primarily to their lower ages and dust exposures.

A similar analysis of the differences (observed FEV $_{1.0}$ - expected $\mathrm{FEV}_{\mathbf{1 . 0}}$ ) was made in relation to the four grades of bronchitis defined from replies to the questionnaire on respiratory symptoms. Table 4 shows that the observed mean FEV $_{1.0}$ among men with chronic bronchitis grades 1, 2, and 3 was lower than expected. Moreover, the discrepancy between the mean value observed and that expected from the fitted equation increases steadily with increasing grade of bronchitis. This indicates the existence of an additional effect on $\mathrm{FEV}_{1.0}$, associated with increasing evidence of respiratory symptoms, which is not accounted for by occupational dust exposure as estimated, smoking or the other variables listed in Table 2 . Table 5 shows the mean values of differences (observed FEV $_{1.0}$-expected FEV $_{1.0}$ ) for 16 subgroups with different combinations of pneumoconiosis and bronchitis. The Table confirms that the additional effect on $\mathrm{FEV}_{\mathbf{1 . 0}}$ associated with increasing severity of bronchitic symptoms is demonstrable both among men with radiological changes indicative of pneumoconiosis and those without.

A separate analysis was made of results from the 2272 men classified as bronchitis grade 0 . Regression coefficients, analogous to those in Table 2 for all subjects, were estimated. The coefficient associated with dust exposure was -0.0005 litre/gh per $\mathrm{m}^{3}$ (that is, a slightly less severe effect than for all 3581 men)and washighly significantstatistically $(\mathrm{P}<0 \cdot 001)$. The effect of smoking among men with bronchitis grade 0 was slightly more severe $(-0.0050$ compared with -0.0046 litre per cigarettes/day for all men). These results demonstrate that measurements of FEV $_{1.0}$ are capable of reflecting impairments of ventilatory capacity associated with dust exposure and smoking, which are not sufficiently severe to be demonstrable in terms of the bronchitis grades used in this study.

Received for publication 8 February 1973

Accepted for publication 30 March 1973 